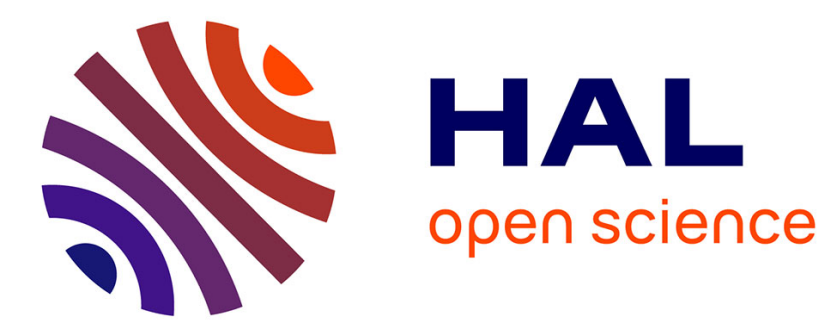

\title{
Effect of sample preservation on stress softening and permanent set of porcine skin
}

A. S. Caro-Bretelle, P. Gountsop, P. Ienny, Romain Léger, S. Corn, I. Bazin, F. Bretelle

\section{- To cite this version:}

A. S. Caro-Bretelle, P. Gountsop, P. Ienny, Romain Léger, S. Corn, et al.. Effect of sample preservation on stress softening and permanent set of porcine skin. Journal of Biomechanics, 2015, 48 (12), pp.3135 - 3141. 10.1016/j.jbiomech.2015.07.014 . hal-01883677

\section{HAL Id: hal-01883677 https://hal.science/hal-01883677}

Submitted on 4 Feb 2020

HAL is a multi-disciplinary open access archive for the deposit and dissemination of scientific research documents, whether they are published or not. The documents may come from teaching and research institutions in France or abroad, or from public or private research centers.
L'archive ouverte pluridisciplinaire HAL, est destinée au dépôt et à la diffusion de documents scientifiques de niveau recherche, publiés ou non, émanant des établissements d'enseignement et de recherche français ou étrangers, des laboratoires publics ou privés. 


\title{
Effect of sample preservation on stress softening and permanent set of porcine skin
}

\author{
A.S. Caro-Bretelle ${ }^{\mathrm{a}, *}$, P.N. Gountsop ${ }^{\mathrm{a}}$, P. Ienny ${ }^{\mathrm{a}}$, R. Leger $^{\mathrm{a}}, \mathrm{S}$. Corn ${ }^{\mathrm{a}}$, I. Bazin ${ }^{\mathrm{c}}$, F. Bretelle ${ }^{\mathrm{b}}$ \\ ${ }^{a}$ C2MA, Ecole des Mines d'Alès, Alès, France \\ b Aix-Marseille Université, Unité de Recherche sur les Maladies Infectieuses Tropicales et Emergentes, UM63, CNRS 7278, IRD 198, INSERM 1095, Marseille, \\ France \\ ${ }^{\mathrm{c}}$ LGEI, Ecole des Mines d'Alès, Alès, France
}

\begin{abstract}
A B S T R A C T
Skin is a composite material with a complex structure which exhibits a wide range of behaviours such as anisotropy, viscoelasticity, hyperelasticity, plasticity etc. Indeed it remains a great challenge to understand its behaviour as it is involved in many consumer and medical applications. In most studies, experiments are performed in situ or in vitro on fresh tissues but most of the time samples are preserved before testing (fridge, freezer, saline solution etc.). In this paper, the impact of samples conservation on the softening behaviour and on the permanent set is studied in order to select the appropriate conservation protocol. Samples are extracted from several pigs' abdomens (direction parallel to spine) and the mechanical testing consists in loading-unloading uniaxial tension tests instrumented with digital image correlation inducing thus reliable strain measurements in a chosen region of interest. The results of this study revealed that preservation conditions must be carefully chosen; conservation in a saline solution and freezing without any caution alter the irreversible part of the global mechanical behaviour of the tissues.
\end{abstract}

Keywords:

Porcine skin

Uniaxial tensile test

Mechanical properties

Sample preservation

Digital image correlation

\section{Introduction}

Studies of the mechanical behaviour of skin are of a great interest since skin strength is involved in many consumer and medical applications. The ultimate goal is to mimic in vivo mechanical behaviour of the skin via in vitro tests. In this context, fresh tissues should be used but in most cases, it is not possible to perform the test directly after the excision, tissues are therefore preserved either bathing in isotonic saline solution or frozen/cooled for various time periods. Many authors have raised the question of the influence of these methods of preservation on the mechanical properties of these tissues, concluding about tissues in vivo properties from tests performed in vitro. The literature is often contradictory concerning the effect of freezing on soft tissues (skin, tendons or ligaments) on mechanical properties. Most of the studies imply monotonic uniaxial tensile tests until breakage and concern freezing procedure with various storage times and temperatures on tendons and ligaments. Some authors assert that freezing at $-20^{\circ} \mathrm{C},-70^{\circ} \mathrm{C}$ or $-80^{\circ} \mathrm{C}$ with or without cryoprotectant for a short period have a moderate effect

\footnotetext{
* Corresponding author. Tel.: + 33 466785631; fax: +33466785680.

E-mail address: Anne-Sophie.Caro@mines-ales.fr (A.S. Caro-Bretelle).

URL: http://www.ema.fr (A.S. Caro-Bretelle).
}

on their elastic properties (O'Leary et al., 2014; Ng and Chou, 2003; Woo et al., 1986; Foutz et al., 1992; Venkatasubramanian et al., 2006; Arnout et al., 2013) while in some others publications the contrary is observed: a decrease (Matthews and Ellis, 1968; Smith et al., 1996; Turner et al., 1988) or an increase (Dorlot et al., 1980; Ng et al., 2005) of mechanical properties. There were even some authors that promote an immediate mechanical testing as the microstructure is strongly affected by the storage (Viidik and Lewin, 1966). In Virues Delgadillo (2010) author perform a biaxial test on human arteries and conclude that freezing at $-20^{\circ} \mathrm{C},-80^{\circ} \mathrm{C}$ during 2 months with DMSO cryoprotectant is the better way to preserve biomechanical properties. From our knowledge there are very few studies on skin tissues; nevertheless the same kind of conclusions can be found in Haut (1989) and Kang and Wu (2011). From a mechanical point of view, some studies were carried out with uniaxial tensile tests and revealed skin anisotropy (Tong and Fung, 1976; Ridge and Wright, 1966) with a stiffer response along Langer's line (aligned with the collagen fibres network). As testing human skin is difficult, various skin specimens have been studied from cats (Veronda and Westmann, 1970), rats (Eshel and Lanir, 2001), mice (Del Prete et al., 2004) or pigs (Ehret et al., 2001). These studies were principally focused on elasticity/failure and viscoelastic properties. In Tong and Fung (1976), Ehret et al. (2001) and Muñoz et al. (2008) authors go further: the experimental protocol is completed via cyclic 
solicitations; as commonly observed for filled elastomers (CaroBretelle et al., 2013), skin exhibits a stress softening usually associated to the preconditioning. In the case of elastomeric materials, recovery of this effect is observed and this preconditioning is often named the Mullins effect. The present study focuses on the influence of porcine skin preservation on stress softening and permanent set. The chosen preservation procedure belongs to laboratories classical equipments such as freezers at $-20^{\circ} \mathrm{C}$ or $-80^{\circ} \mathrm{C}$ and saline solutions for several storage times. The tests were performed on skin samples extracted in parallel with tissue fibres. The softening effect and permanent set were investigated by cyclic loading with different load levels and for one loading rate. The tests are instrumented by photomechanics allowing overcoming experimental difficulties. The originality of the study is both the experimental procedure (cyclic tensile tests instrumented by photomechanics) and the required mechanical properties both in the reversible and irreversible range (elasticity, damage, permanent set etc.) in link with conservation procedure.

\section{Materials and methods}

\subsection{Sample preparation}

Skin tissue is mainly constituted (in term of dry weight) with a collagen fibres network (65-70\%), some elastin fibres (5-10\%) and proteoglycan (1.5-2\%). Collagen is stiffer that elastin but absorbs more energy (Usyk and Mcculloch, 2002). As collagen structure in tissues changes with disease and ageing, the pigs (4) are chosen with approximatively the same weight and age. They are obtained within $24 \mathrm{~h}$ after the slaughtering from the abdominal region following Langer's line. The skins samples are obtained from a local slaughterhouse under the animals welfare regulations. Samples are punched out from the pressurized skin $30^{*} 100 \mathrm{~mm}^{2}$ in size. Symmetrical notches were then perforated using a sharp punch cut in order to induce a strain localisation during mechanical testing (Fig. 1). This shape, named double-edge notched tensile (DENT), allows initiating necking between notches, in the area in front of which a camera is placed (Christmann et al., 2011). The radius curvature of $1 \mathrm{~mm}$ is used to keep the tensile load uniaxial: the stress heterogeneity remains inferior to $5 \%$. The hypodermis was removed with a surgical scalpel. The average thickness $(h)$ was measured with a calliper spanning the length of the sample in 4 different locations for all specimens (84); no significant difference was detected between them; the value of the thickness is evaluated around: $2 \pm 0.3 \mathrm{~mm}$

For each porcine, 21 skin specimens were preserved before testing following several procedures, as it is mentioned in Table 1 :

- 9 were bathed in a normal saline solution and kept in fridge $\left(4^{\circ} \mathrm{C}\right)$ during 4,24 or $72 \mathrm{~h}$.

- 3 of them were fresh frozen at $-20^{\circ} \mathrm{C}$ for one week with a decrease in temperature of about $1{ }^{\circ} \mathrm{C}$ per minute,

- 3 were fresh frozen at $-80^{\circ} \mathrm{C}$ for one week with a decrease in temperature of about $1{ }^{\circ} \mathrm{C}$ per minute,
- 3 were fresh frozen in freezing medium (Phosphate Buffered Saline (PBS) plus cryoprotectant) for one week. The cryoprotectants used alone were glycerol $(10 \%)$, or trehalose $(60$ and $100 \mathrm{mM})$. The cryovials $(25 \mathrm{ml})$ containing the samples (which were no folded) were placed in an isopropanol chamber and store them at $-80^{\circ} \mathrm{C}$ for one week in order to allow a decrease in temperature of about $1{ }^{\circ} \mathrm{C}$ per minute.

- 3 were preserved in fridge $\left(4^{\circ} \mathrm{C}\right)$ and tested within the 2 first hours of conservation. They constitute our reference.

Frozen specimens are thawed at controlled temperature and humidity during 1 hour prior to testing. The samples bathed in a saline solution were blotted with absorbent paper to avoid presence of any excess saline solution.

\subsection{Instrumented tensile test and digital image correlation}

The uniaxial tensile tests were performed using a Dartec universal test setup at ambient temperature. Because some studies refer to mechanical and environmental change as testing temperature or loading rate due to a collagen denaturation (Zhou et al., 2010; Kang and Wu, 2011), tests conducted in the present study were performed with a constant crosshead speed equal to $0.5 \mathrm{~mm} / \mathrm{min}$. The material and geometrical heterogeneities lead to variable loading rate which can induce damage in the extra-cellular matrix. The ends of the specimens (sections $40 * 30 \mathrm{~mm}^{2}$ ) were gripped between specially adapted jaws of the tensile test device (see Fig. 1). They were subjected to non-monotonic loadings (Fig. 2):

- two loading-unloading cycles at $10 \mathrm{kN}, 20 \mathrm{kN}$ and $50 \mathrm{kN}$; the unloading procedure being performed until the load reached zero.

- The last cycle at $50 \mathrm{kN}$ is followed by a loading until breakage.

The nominal stress $(\boldsymbol{\sigma})$ is defined as the ratio between the uniaxial force recorded by the test equipment $(\boldsymbol{F})$ and the initial area at the minimal cross-sectional of the sample $\left(\boldsymbol{A}_{0}=\boldsymbol{L}_{0} \boldsymbol{h}, \boldsymbol{L}_{0}\right.$ is the initial width at the minimal cross section) as described in Eq. (1):

$\sigma=F / A_{0}$

Table 1

Conservation protocol.

\begin{tabular}{lll}
\hline Tests & Conservation methods & $\begin{array}{l}\text { \#Specimens (\#samples } \\
\text { per specimen) }\end{array}$ \\
\hline 4 pigs $\left(\mathrm{c}_{1}, \mathrm{c}_{2}, \mathrm{c}_{3}, \mathrm{c}_{4}\right)$ & $+4{ }^{\circ} \mathrm{C}$ during 2 $\mathrm{h}$ (Ref) & $4(3,3,3,3)$ \\
3 samples by tests 84 & $-20^{\circ} \mathrm{C}$ during 7 days & $4(3,3,3,3)$ \\
tests & $-80^{\circ} \mathrm{C}$ during 7 days & $4(3,3,3,3)$ \\
& $-80^{\circ} \mathrm{C}$ (cryopreserved) & $4(3,3,3,3)$ \\
& during 7 days & \\
& Saline solution during 4h & $4(3,3,3,3)$ \\
& Saline solution during & $4(3,3,3,3)$ \\
& 24 h & \\
& Saline solution during & $4(3,3,3,3)$ \\
& $72 \mathrm{~h}$ & \\
\hline
\end{tabular}

a

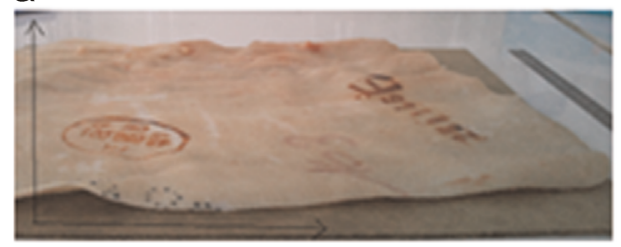

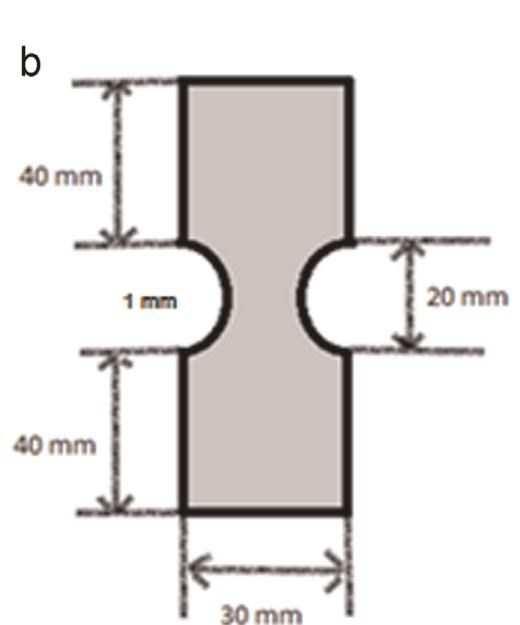

C
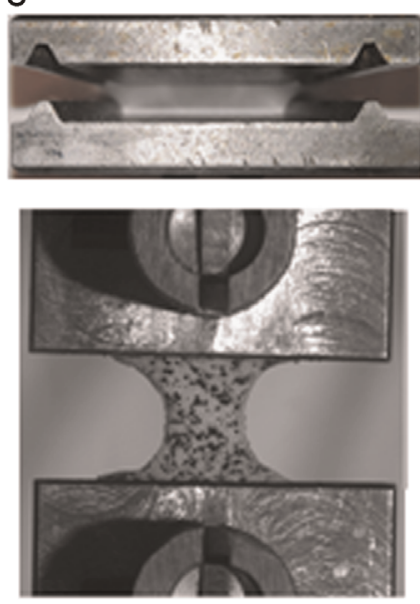

Fig. 1. Native porcine skin before punching (a) useful dimension of specimens (thickness $2 \mathrm{~mm}$ ) (b) sample gripped in its initial state (c). 
During the tensile tests, the displacement of points within a specific surface area centred on the minimum section of the specimen, area also named Zone of Interest (ZOI), is continuously measured. For this purpose, a CCD camera (Redlake Megaplus II) was placed in front of the specimen, and the optical axis was kept perpendicular to the surface of the sample. Image sequences were recorded at successive states of the deformation every $1 \mathrm{~s}$ during the mechanical test. The scale factor is fixed to $0.1 \mathrm{~mm}$ per pixel. The two-dimensional in-plane displacements are performed using correlation calculations involving digital-image processing (CinEMA $^{\mathbb{R}}$ software). The procedure is fully described in Caro-Bretelle et al. (2013). The first image enables the evaluation of the minimum cross section area $\boldsymbol{A}_{0}$ for each test.

Image correlation or 'map-matching' techniques, widely used to compare two signals, are part of an optical method used to measure the displacement fields on a surface sample by comparing pictures acquired at different states of strain. Before the test, the inspected sample surface was sprayed with a thin layer of black carbon to give it an artificial granular appearance that is similar to optical speckle (see image signature in Fig. 2).

The in-plane strains of the central point of the ZOI are directly evaluated by derivative of the displacements field obtained at the neighbouring points and the components of the in-plane Green-Lagrange strain tensor, E, can be expressed by the formula in Eq. (2):

$\mathbf{E}=1 / 2\left(\mathbf{F}^{\mathrm{T}} \mathbf{F}-\mathbf{I}\right), \mathbf{F}=\frac{\partial x(X)}{\partial X}, \quad u(X)=x(X)-X$

where $x(X)$ maps the initial coordinate, $\boldsymbol{X}$, onto the current coordinate, $\boldsymbol{x}$, of a material particle and $\boldsymbol{u}$ is the displacement vector. Capital boldface letters refer to second-order tensors.

Let $\boldsymbol{y}$ be the tensile direction, $\boldsymbol{z}$ be the out-of-plane direction and $\boldsymbol{x}-\boldsymbol{y}$ be the planar surface such that $(\boldsymbol{x}, \boldsymbol{y}, \boldsymbol{z})$ is an orthonormal basis; $u_{x}, u_{y}, u_{z}$ refer to the projection of the displacement vector according to $\boldsymbol{x}, \boldsymbol{y}$ and $\boldsymbol{z}$. The components of the 2D Green-Lagrange strain tensor, denoted by $E_{x x}, E_{y y}, E_{x y}$, are thus evaluated. For sake of simplicity, $E_{x x}$ and $E_{y y}$ will be denoted by $E_{x}$ and $E_{y}$. The induced strain was computed as follows:

$\varepsilon_{i}=\lambda_{i}-1, \lambda_{i}=\sqrt{2 E_{i}+1}, i=x, y, x y$,

where $\lambda_{i}$ are stretch ratios.

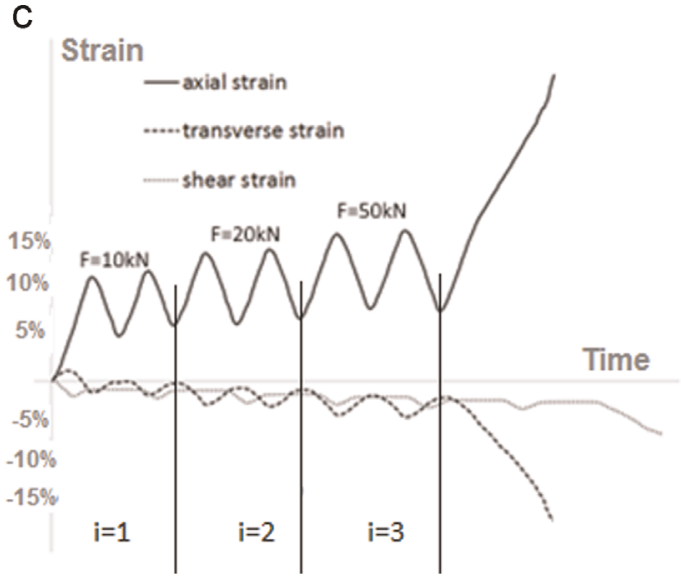

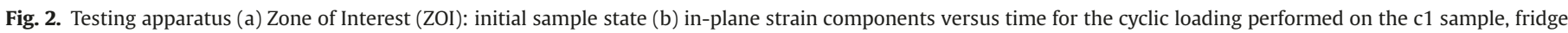
preserved (c).
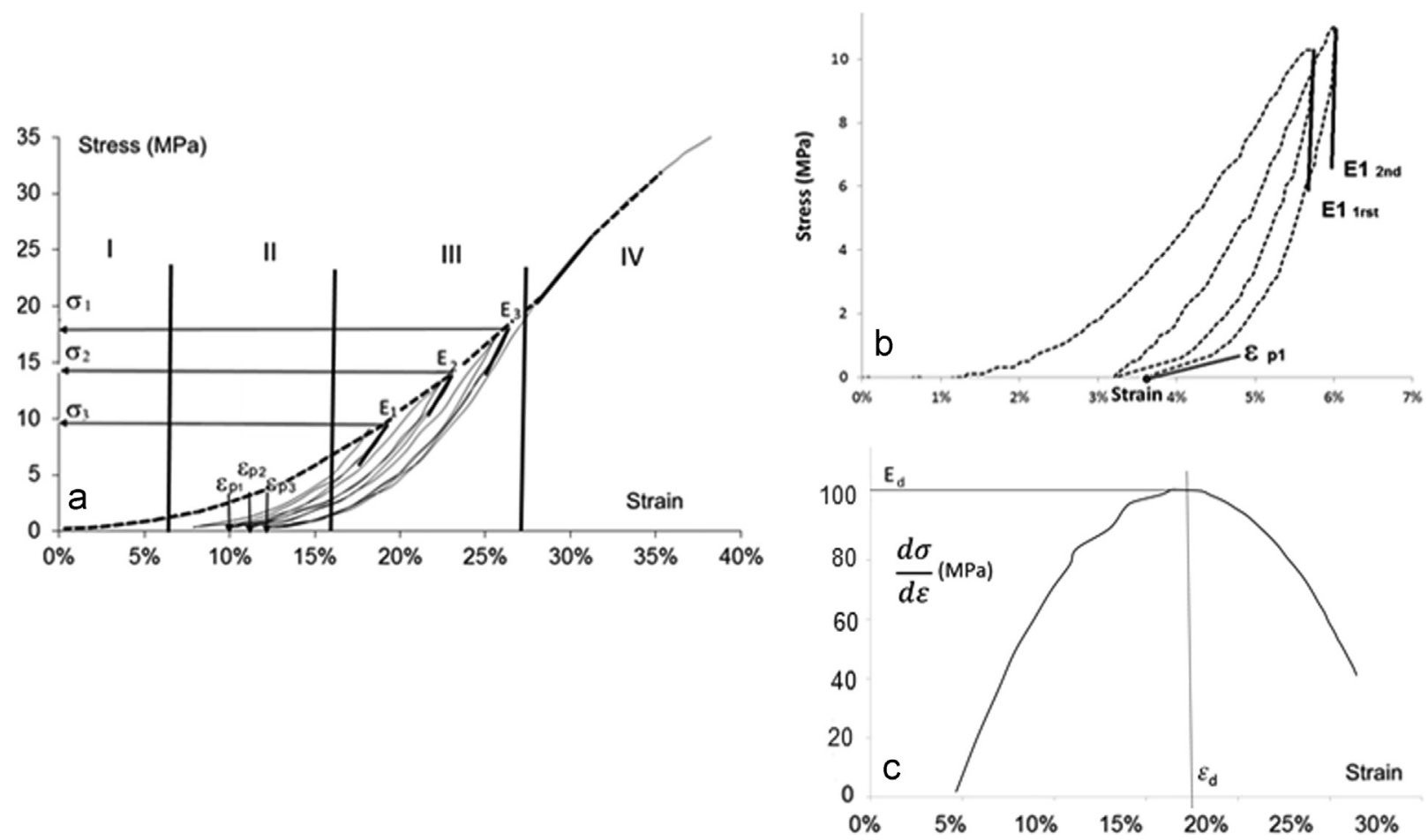

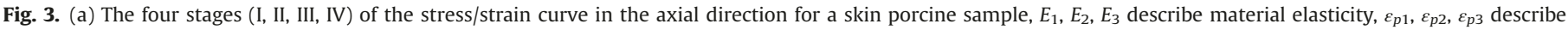

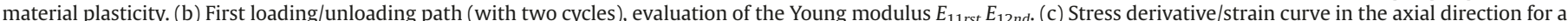
skin porcine sample, identification of the beginning of the damage process $\left(\varepsilon_{d}, E_{d}\right)$. 
In Fig. 2c, typical strain evolutions are plotted versus time (exemple given for the skin sample c1 preserved in fridge). The axial and transverse strain $\left(\varepsilon_{x}, \varepsilon_{y}\right)$ evolutions follow the imposed cycles; the transverse $\left(\varepsilon_{x}\right)$ and shear strain $\left(\varepsilon_{x y}\right)$ remain negligible at least before the sample breakage. This protocol is repeated for each test to ensure the simple tensile test hypothesis.

\subsection{Phenomenological description}

A total of 84 cyclic uniaxial tests were performed. The mechanical response in the axial direction is described in Fig. 3a. Four stages can be distinguished from the monotonic stress/strain curve (dotted line in Fig. 3a). In the phase I, collagen fibres are in a relaxed state and the elastin fibres are responsible for the elastic response. In the second stage, collagen fibres tend to line up with the load direction, the crimped collagen fibres gradually elongate and they interact with the hydrated matrix. In the third one, the crimp patterns disappear and the collagen fibres become straighter, which results in the increase of the slope of the stress/strain curve. They are primarily aligned with one another in the direction in which the load is applied. The straightened collagen fibres strongly resist the load and the tissue becomes stiffer at higher stress levels. Beyond the third phase the ultimate tensile strength is reached and fibres begin to break (Usyk and Mcculloch, 2002). The in plane spacial variation of collagen fibre bundles in the porcine skin has been already investigated microscopically in term of a standard iron-hematoxylin staining method (Zhou et al., 2010). Otherwise the loading/unloading cycles show a significant part of a strain-induced stress-softening effect of the material. In a previous study (Liu and Yeung, 2008) the hysteresis stability (when the mechanical response is reproducible from cycle to cycle) is found to be reached after a number of cycles greater than 4-6 cycles. In our study two loading/unloading cycles have been performed at 10,20 and $50 \mathrm{kN}$ so the material stability was not reached. By remembering that two loading-unloading cycles at $10 \mathrm{kN}, 20 \mathrm{kN}$ and $50 \mathrm{kN}$ are performed, the material elasticity is described through the slope measurement of the stress/strain curve at the beginning of the two unloading steps and for each loading level: two parameters are therefore obtained: $E_{i 1 r s t}, E_{i 2 n d}=, i=1,2,3$ by analogy with Young's modulus (see Fig. 3b). To complete this analysis, a damage parameter, which describes the beginning of the stress softening, is introduced from the stress derivative of the monotonic stress/strain curve (dotted line in Fig. 3a). A typical evolution of $d \sigma / d \varepsilon$ with respect to $\varepsilon_{y}$ can be observed in Fig. 3c. In conventional manner, the value $\varepsilon_{d}$ will be assimilated to the beginning of a damage process and $E_{d}$ to the associated modulus. Finally, the values of plastic parameters after each unloading cycle are also reported and will be denoted $\varepsilon_{p i}, i=1,2,3$ (see Fig. 3a and b).

In this paper we choose a phenomenological response characterisation via well-chosen slopes of the stress/strain response. An alternative (and it is a perspective of this work) should be the use of parameters of an adequate modelling (Lokshin and Lanir, 2009).

\section{Results and discussion}

\subsection{Mechanical response variability}

Skin is known for its large response variability from a subject to another and from two sample locations on a same subject (Vardaxis et al., 1997).

Fig. 4 shows the stress/strain responses of two specimens from four different porcine skins preserved with the reference protocol (namely c1, c2, c3, c4). This phenomenological response is interpreted via the parameters $E_{i 1 r s t}, E_{i 2 n d}, \varepsilon_{p i}, i=1,2,3$ and $E_{d}, \varepsilon_{d}$. These values are reported in Table 2 . We can notice a good reproducibility between two tests performed on a same subject (dispersion never exceeding 5\%) which assess the repeatability of the mechanical testing protocol.

Fig. 5 shows the stress/strain response of 4 samples extracted from 4 different subjects. The global response is qualitatively the same. Nevertheless the characterisation via the parameters introduced previously reveals (by mean of global average), some discrepancies between samples provenance: the Relative Standard Deviation (i.e. ratio between the Standard Deviation and the mean
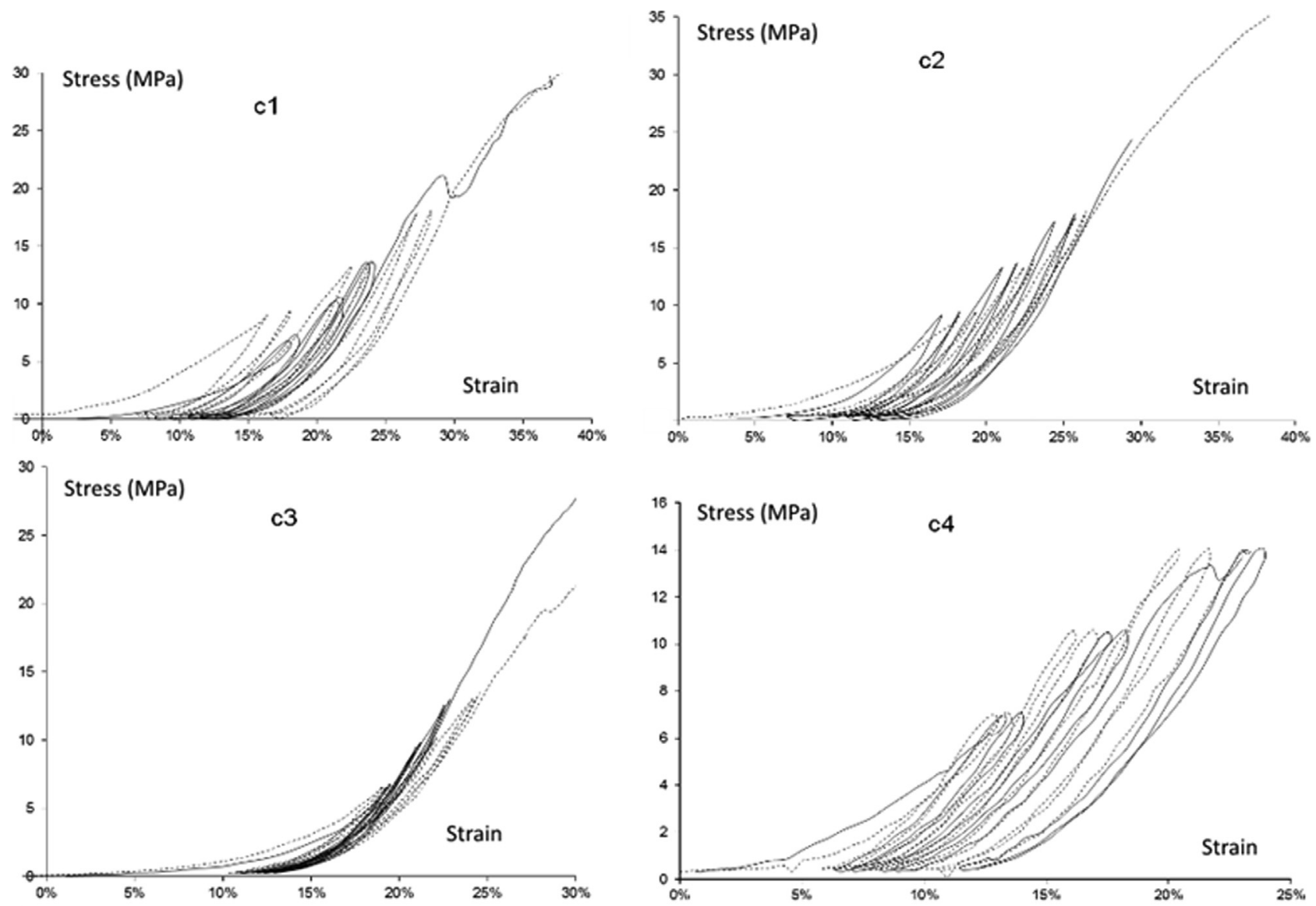

Fig. 4. : Stress/strain curves illustrating the intra-subject reproducibility. 
Table 2

Inter and intra-subject modulus $E_{i 1 r s t}, E_{i} 2$ nd, $i=1,2$ 3 , damage $E_{d} \varepsilon_{d}$ and plastic parameters $\varepsilon_{p i, i=1,2}$.

\begin{tabular}{|c|c|c|c|c|c|c|c|c|}
\hline & $E_{1}(\mathrm{MPa}) E_{11 r s t} E_{12 \text { 2nd }}$ & $E_{2}(\mathrm{MPa}) E_{2} 1 r s t E_{2}$ 2nd & $E_{3}(\mathrm{MPa}) E_{3} 1 r s t E_{3} 2$ nd & $E_{d}(\mathrm{MPa})$ & $\varepsilon_{d}$ & $\varepsilon_{p 1}$ & $\varepsilon_{p 2}$ & $\varepsilon_{p 3}$ \\
\hline \multirow[t]{2}{*}{ c1 } & $116 \mp 6$ & $218 \mp 5$ & $242 \mp 6$ & $104 \mp 5$ & $0.33 \mp 0.001$ & $0.14 \mp 0.006$ & $0.18 \mp 0.002$ & $0.23 \mp 0.002$ \\
\hline & $114 \mp 6$ & $205 \mp 5$ & $231 \mp 6$ & & & & & \\
\hline \multirow[t]{2}{*}{ c2 } & $136 \mp 2$ & $216 \mp 4$ & $247 \mp 7$ & $139 \mp 3$ & $0.27 \mp 0.002$ & $0.09 \mp 0.002$ & $0.2 \mp 0.005$ & $0.12 \mp 0.005$ \\
\hline & $135 \mp 2$ & $203 \mp 4$ & $226 \mp 7$ & & & & & \\
\hline \multirow[t]{2}{*}{ c3 } & $143 \mp 4$ & $241 \mp 3$ & $243 \mp 6$ & $133 \mp 6$ & $0.28 \mp 0.004$ & $0.13 \mp 0.009$ & $0.14 \mp 0.003$ & $0.15 \mp 0.008$ \\
\hline & $141 \mp 4$ & $202 \mp 3$ & $222 \mp 6$ & & & & & \\
\hline \multirow[t]{2}{*}{ c4 } & $123 \mp 5$ & $124 \mp 4$ & $189 \mp 9$ & $99 \mp 3$ & $0.22 \mp 0.003$ & $0.06 \mp 0.002$ & $0.08 \mp 0.002$ & $0.1 \mp 0.003$ \\
\hline & $120 \mp 5$ & $121 \mp 4$ & $178 \mp 9$ & & & & & \\
\hline \multirow[t]{2}{*}{ Mean values (MPa) } & $129 \mp 20$ & $200 \mp 50$ & $230 \mp 50$ & $119 \mp 22$ & $0.27 \mp 0.03$ & $0.1 \mp 0.04$ & $0.15 \mp 0.05$ & $0.15 \mp 0.06$ \\
\hline & $127 \mp 20$ & $183 \mp 50$ & $214 \mp 50$ & & & & & \\
\hline \multirow[t]{2}{*}{$\mathrm{SD}^{\mathrm{a}}(\mathrm{MPa})$} & 10.6 & 44.8 & 23.9 & 17.5 & 0.04 & 0.04 & 0.05 & 0.05 \\
\hline & 10.9 & 35.7 & 21.2 & & & & & \\
\hline \multirow[t]{2}{*}{$\mathrm{RSD}^{\mathrm{b}} \%$} & 8.2 & 22.4 & 10.4 & 14.7 & 14.2 & 30.3 & 30.5 & 33.0 \\
\hline & 8.6 & 19.5 & 9.9 & & & & & \\
\hline
\end{tabular}

a SD : Standard Deviation.

${ }^{\mathrm{b}} \mathrm{RSD}$ : Relative Standard Deviation.

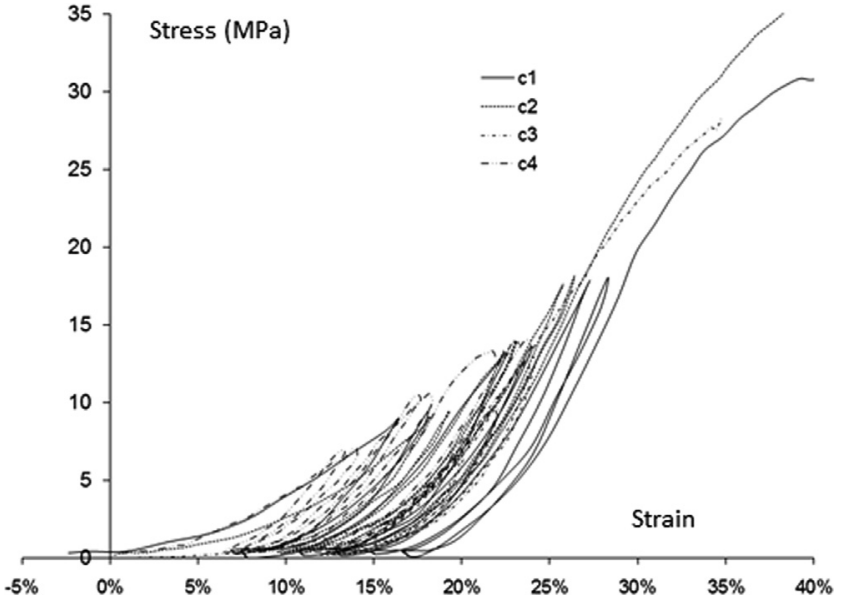

Fig. 5. : Stress/strain curves illustrating the inter-subject variability.

value) reaches $33 \%$ for the parameter $\varepsilon_{p 3}$ in Table 2, discrepancies probably imputed to microstructural change (quantity and quality of collagen and elastin fibres); to go further with this analysis a protocol to quantify the collagen quantity should be adopted.

\subsection{Impact of conservation protocol on the mechanical response of tissues}

Now that skin behaviour has been described, the impact of preservation conditions can be studied. Given test repeatability and known intra-sample and inter-sample reproducibility, mean moduli after each loading/unloading sequence are displayed, in Fig. 6 where "ref» corresponds to samples preserved at $4{ }^{\circ} \mathrm{C}$ during $2 \mathrm{~h}$, " $\mathrm{T}-20^{\circ} \mathrm{C}$ " to freezed samples at $-20^{\circ} \mathrm{C}$, «T $-80^{\circ} \mathrm{C}$ " to freezed samples at $-80^{\circ} \mathrm{C}$, «T $-80^{\circ} \mathrm{C}$ cryoprotected» to freezed at $-80^{\circ} \mathrm{C}$ and cryoprotected samples, "saline solution" to samples immersed in saline solution during 4,24 or $72 \mathrm{~h}$. First of all, modulus increased during the three first cycles for all samples which is in total accordance with the microdeformation of elastin and collagen during the process (Usyk and Mcculloch, 2002). The freezing at $-20^{\circ} \mathrm{C}$ seems to maintain elastic properties as the three values are of the same order compared with reference. This result is in accordance with other studies from Moon et al. (2006) and O'Leary et al. (2014). Some studies on articular cartilage found no difference in collagen content released from tissue with respect to the conservation protocol (Szarko et al., 2010) which could explain the maintain of elastic properties. Concerning the freezing at $-80^{\circ} \mathrm{C}$ with and without cryopreservation, the first moduli is higher than the following and significantly lower in comparison with the reference sample; it is known that, for such conservation temperatures, the structural network of collagen is modified due to dehydration; collagen network might be disorganised or disrupted thus inducing variation in mechanical response.

Finally, from the viewpoint of the modulus and in a not expected way, the immersion in a saline solution during a short time enhances the elastic properties. For longer immersion time material properties fall drastically to reach the one of fresh tissues but show an unexpected large increase between $10 \mathrm{kN}$ and $20 \mathrm{kN}$. The samples bath during $72 \mathrm{~h}$ in the saline solution break before reaching the final level of loading. This may be due to the plasticizing effect of water: water molecules increase chain mobility within the tissue (Matveev et al., 2000). Nevertheless, damage parameters will indicate a material degradation associated with this kind of conservation (from $24 \mathrm{~h}$ ) (see Section 4). A last observation concerns the material stability (difference between first and second unloading). We can notice a decrease in the modulus between the first and the second unloading: this is the stress softening. Even if the stabilisation is not reached, a tendency can be exacerbated: the freezing at $-80^{\circ} \mathrm{C}$ emphasises the stress softening, for all the level of loading; the bathing during $72 \mathrm{~h}$ has the same effect for the second level of loading.

Concerning the plastic parameters, the irreversible plastic strain which is associated to the permanent set seems to be equivalent for all the samples regarding to the large variability of this parameter. The freezing at $-80^{\circ} \mathrm{C}$ with no cryopreservant conduces to a large value of the irreversible damage (Fig. 7). This phenomenon confirms that the microstructure must be affected by this conservative temperature (by breaking microstructural bonds for example) and thus the necessity of cryopreservant additives. Adding cryopreservant leads to a delaying of the onset of plasticity. Freezing without any precaution modify the damage parameters. Fig. 8 presents the evolution of damage parameters $E_{d}, \varepsilon_{d}$ for all the tested conservation protocols. $\varepsilon_{d}$ is related to the beginning of damage and $E_{d}$ is the tangent modulus corresponding to the strain $\varepsilon_{d}$. Low values of these parameters are associated to a material degradation and thus to an unfavourable conservation protocol. It appears that freezing without any precaution ( $T-20^{\circ} \mathrm{C}$, «T $-80{ }^{\circ} \mathrm{C}$ " ) induces a premature damage (i.e. a lower $\varepsilon_{d}$ ) for the specimens attributed for some authors to cellular crystallisation 


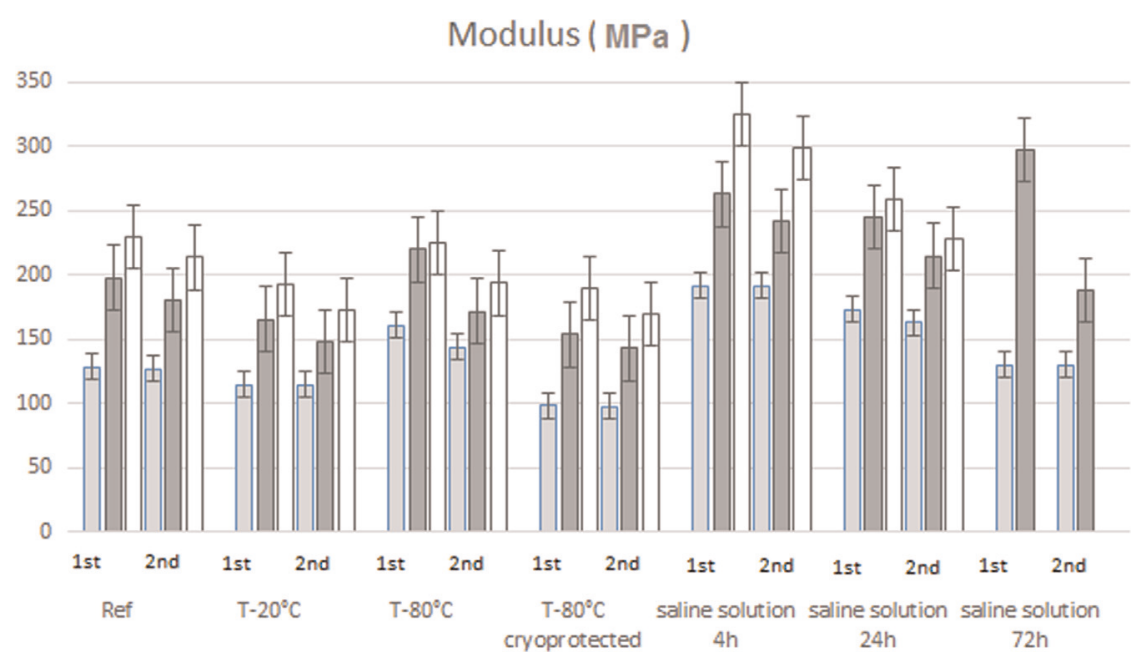

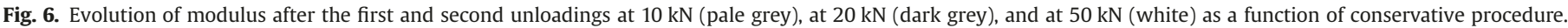

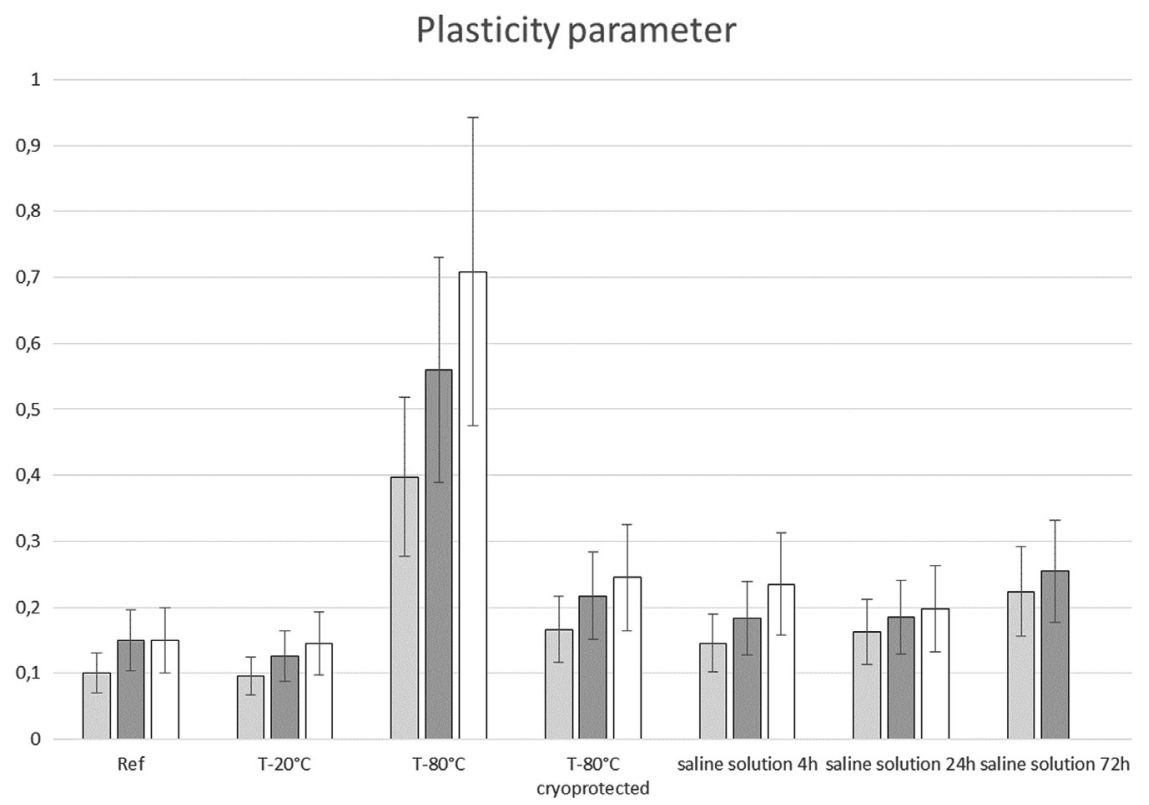

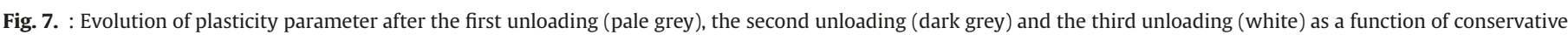
procedure.

and cell bursting, small vessel damage (Lagerveld et al., 2010) or ice lens formation (Szarko et al., 2010). Another explanation could be the loss of water during thawing due to evaporation (Ternifi et al., 2013), nevertheless this option has been excluded since all the samples have been thawed with the same protocol: equivalent time, temperature and humidity. Furthermore, microstructural modifications observed by Giannin et al. (2008) on human posterior tibial tendons induced by the freezing could be responsible for the mechanical properties alterations. TEM showed an increase in the mean diameter of collagen fibrils and in fibril non-occupation mean ratio, while the mean number of fibrils decreased. The cryopreservant protects the microstructure and delay the beginning of damage. According to Szarko et al. (2010) the storage in PBS would provide an opportunity for the tissue to response to the presence of collagen damage, likely becoming over-hydrated. Finally, conservation in saline solution during a short time seems to maintain the damage kinetic at least before $24 \mathrm{~h}$ of conservation, after that the material degradation induced by the bathing leads to a damage kinetic equivalent to the one of freezing without precaution. All the conservation protocol seems to be equivalent concerning the tangent stress module reached at the beginning of the damage process, expected the freezing at $-80{ }^{\circ} \mathrm{C}$ without cryopreservation: the material is stiffer in this case. An increase in physiological elastic modulus has been already observed by the team of Venkatasubramanian et al. (2006) on arteries.

\section{Conclusions}

This paper examines the robustness of different methods of conservation (physical and/or chemical) on the mechanical response of biological tissues such as skin. An experimental protocol has been developed to compare, for a controlled storage time, several conservation procedures currently available in laboratories (freezing, saline bathing, fridge). Several key results have emerged from this work: any method of conservation introduces a change in the mechanical behaviour of the biological tissue. An experimental Taylor made methodology has been defined, associating non-contact measurements of strain, cyclic loading and phenomenological analysis based on specific set of 
$\varepsilon d$
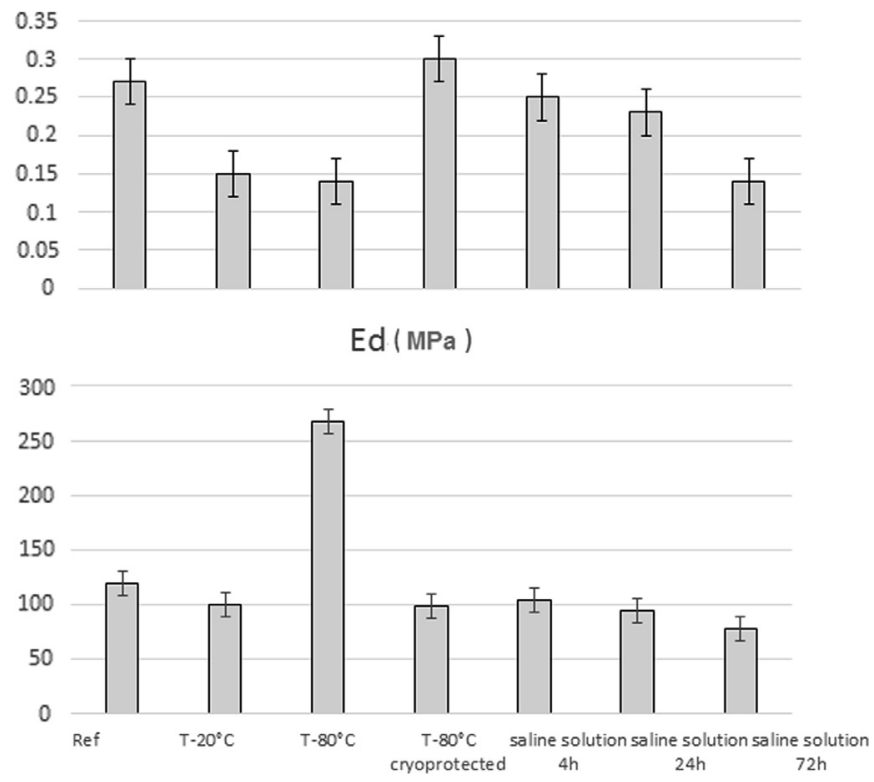

Fig. 8. : Evolution of damage parameters as a function of conservative procedure.

parameters associated with the overall behaviour. A simple storage at $-20^{\circ}$ alters the mechanical behaviour of the tissue except of its elastic response. Cryopreservation is the only conservation way to maintain the mechanical behaviour of fresh tissues (even delaying the beginning of damage phenomena). Finally bathing in saline solution alters global mechanical behaviour. A perspective of this work is to associate mechanical and microstructural characterisation via the analysis of damage tissue. The effects of cryopreservation on collagen integrity by histological analyses and collagen levels analyses have to be performed. The use of others cryoprotectants like EG (ethylene glycol) or DMSO (Dimethyl sulfoxide) for cryopreservation can be performed too.

\section{Conflict of interest statement}

None.

\section{Acknowledgement}

The authors are indebted to the local butcher of Moussac for supplying pig's skin.

\section{References}

Arnout, N., Myncke, J., Vanlauwe, J., Labey, L., Lismont, D., Bellemans, J., 2013. The influence of freezing on the tensile strength of tendon grafts: a biomechanical study. Acta Orthop. Belg. 79 (4), 435-443.

Caro-Bretelle, A.S., Ienny, P., Leger, R., 2013. Constitutive modeling of a SEBS castcalender: large strain, compressibility and anisotropic damage induced by the process. Polymer 54, 4594-4603.

Christmann, A., Ienny, P., Quantin, J.C., Caro-Bretelle, A.S., Lopez-Cuesta, J.M., 2011. Mechanical behaviour at large strain of polycarbonate nanocomposites during uniaxial tensile test. Polymer 52 (18), 4033-4044.

Del Prete, Z., Antoniucci, S., Hoffman, A.H., Grigg, P., 2004. Viscoelastic properties of skin in Mov-13 and Tsk mice. J. Biomech. 37 (10), 1491-1497.

Dorlot, J.M., Ait Ba Sidi, M., Tremblay, G.M., Drouin, G., 1980. Load elongation behavior of the canine anterior cruciate ligament. J. Biomech. Eng. 102 (3), 190.
Ehret, A.E., Hollenstein, M., Mazza, E., Itskov, M., 2001. Porcine dermis in uniaxial cyclic loading: sample preparation, experimental results and modeling. J. Mech. Mater. Struct. 6 (7-8), 1125-1135.

Eshel, H., Lanir, Y., 2001. Effects of strain level and proteoglycan depletion on preconditioning and viscoelastic responses of rat dorsal skin. Ann. Biomed. Eng. 29 (2), 164-172.

Foutz, T.L., Stone, E.A., Abrams, C.F., 1992. Effects of freezing on mechanical properties of rat skin. Am. J. Vet. Res. 53 (5), 788-792.

Giannini, S., Buda, R., Di Caprio, F., Agati, P., Bigi, A., De Pasquale, V., Ruggeri, A., 2008. Effects of freezing on the biomechanical and structural properties of human posterior tibial tendons. Int. Orthop. 32 (2), 145-151.

Haut, R.C., 1989. The effects of orientation and location on the strength of dorsal rat skin in high and low speed tensile failure experiments. J. Biomech. Eng. 111 (2), 136-140.

Kang, G., Wu, X., 2011. Ratchetting of porcine skin under uniaxial cyclic loading. J. Mech. Behav. Biomed. Mater. 4 (3), 498-506.

Lagerveld, B.W., van Horssen, P., Pes, M.P.L., van den Wijngaard, J.P.H.M., Streekstra, G.J., de la Rosette, J.J.M.C.H., Spaan, J.A.E., 2010. Immediate effect of kidney cryoablation on renal arterial structure in a porcine model studied by imaging cryomicrotome. J. Urol. 183 (3), 1221-1226.

Liu, Z., Yeung, K., 2008. The preconditioning and stress relaxation of skin tissue. J. Biomed. Pharm. Eng. 1, 22-28.

Lokshin, O., Lanir, Y., 2009. Viscoelasticity and preconditioning of rat skin under uniaxial stretch: microstructural constitutive characterization. J. Biomech. Eng. 131 (3), 031009

Matthews, L.S., Ellis, D., 1968. Viscoelastic properties of cat tendon: effects of time after death and preservation by freezing. J. Biomech. 1 (2), 65-71.

Matveev, Y.I., Grinberg, V.Y., Tolstoguzov, V.B., 2000. The plasticizing effect of water on proteins, polysaccharides and their mixtures. Glassy state of biopolymers, food and seeds. Food Hydrocoll. 14 (5), 425-437.

Moon, D.K., Woo, S.L.Y., Takakura, Y., Gabriel, M.T., Abramowitch, S.D., 2006. The effects of refreezing on the viscoelastic and tensile properties of ligaments. J. Biomech. 39 (6), 1153-1157.

Muñoz, M.J., Bea, J.A., Rodríguez, J.F., Ochoa, I., Grasa, J., Pérez del Palomar, A. Doblaré, M., 2008. An experimental study of the mouse skin behaviour: damage and inelastic aspects. J. Biomech. 41 (1), 93-99.

Ng, B.H., Chou, S.M., Lim, B.H., Chong, A., 2005. The changes in the tensile properties of tendons after freeze storage in saline solution. Proc. Inst. Mech. Eng. Part H: J. Eng. Med. 219 (6), 387-392.

Ng, B.-H., Chou, S.-M., 2003. The effect of freeze storage on the tensile properties of tendons. J. Mech. Med. Biol. 3 (4), 299-308.

O'Leary, S.A., Doyle, B.J., McGloughlin, T.M., 2014. The impact of long term freezing on the mechanical properties of porcine aortic tissue. J. Mech. Behav. Biomed. Mater. 37, 165-173.

Ridge, M., Wright, V., 1966. The directional effects of skin. J. Investig. Dermatol. 46 (4), 341-346.

Smith, C.W., Young, I.S., Kearney, J.N., 1996. Mechanical properties of tendons: changes with sterilization and preservation. J. Biomech. Eng. 118 (1), 56-61.

Szarko, M., Muldrew, K., Bertram, J.E., 2010. Freeze-thaw treatment effects on the dynamic mechanical properties of articular cartilage. BMC Musculoskelet. Disord. 11, 231.

Ternifi, R., Gennisson, J.-L., Tanter, M., Beillas, P., 2013. Effects of storage temperature on the mechanical properties of porcine kidney estimated using shear wave elastography. J. Mech. Behav. Biomed. Mater. 28, 86-93.

Tong, P., Fung, Y.C., 1976. The stress-strain relationship for the skin. J. Biomech. 9 (10), 649-657.

Turner, W.D., Vasseur, P., Gorek, J.E., Rodrigo, J.J., Wedell, J.R., 1988. An in vitro study of the structural properties of deep-frozen versus freeze-dried, ethylene oxidesterilized canine anterior cruciate ligament bone-ligament-bone preparations. Clin. Orthop. Relat. Res. 230, 251-256.

Usyk, T.P., Mcculloch, A.D., 2002. Computational methods for soft tissue biomechanics. Biomech. Soft Tissue Cardiovasc. Syst. 441, 273-342.

Vardaxis, N.J., Brans, T.A., Boon, M.E., Kreis, R.W., Marres, L.M., 1997. Confocal laser scanning microscopy of porcine skin: implications for human wound healing studies. J. Anat. 190, 601-611.

Venkatasubramanian, R.T., Grassl, E.D., Barocas, V.H., Lafontaine, D., Bischof, J.C., 2006. Effects of freezing and cryopreservation on the mechanical properties of arteries. Ann. Biomed. Eng. 34 (5), 823-832.

Veronda, D.R., Westmann, R.A., 1970. Mechanical characterization of skin-finite deformations. J. Biomech. 3 (1), 111-124.

Viidik, A., Lewin, T., 1966. Changes in tensile strength characteristics and histology of rabbit ligaments induced by different modes of postmortal storage. Acta Orthop. Scand. 37 (2), 141-155.

Virues Delgadillo, J.O., 2010. Effect of freezing on the passive mechanical properties of arterial samples. J. Biomed. Sci. Eng. 3 (7), 645-652.

Woo, S.L., Orlando, C.A., Camp, J.F., Akeson, W.H., 1986. Effects of postmortem storage by freezing on ligament tensile behavior. J. Biomech. 19 (5), 399-404.

Zhou, B., Xu, F., Chen, C.Q., Lu, T.J., 2010. Strain rate sensitivity of skin tissue under thermomechanical loading. Philos. Trans. Ser. A: Math. Phys. Eng. Sci. 368 (1912), 679-690. 